\title{
Electrochemical Reduction of Halobenzenes in the Presence of Carbon Dioxide
}

\author{
Tomokazu MATSUE*, Shinichi KitAhARA* and Tetsuo OSA*
}

\begin{abstract}
The electrochemical reduction of halobenzenes in the presence of $\mathrm{CO}_{2}$ on a $\mathrm{Hg}$ cathode was investigated. The reduction of iodobenzene and bromobenzene under $\mathrm{CO}_{2}$ yielded benzoic acid as a fixation product of $\mathrm{CO}_{2}$. However, the reduction of $\mathrm{CO}_{2}$ in the presence of chlorobenzene produced no benzoic acid. It is confirmed that the reduction of halobenzenes is important to fixate $\mathrm{CO}_{2}$ on phenyl group and the reaction of $\mathrm{CO}_{2}{ }^{-}$with halobenzenes is slow. In the present electrolysis, the phenylmercury radical is considered as an intermediate for the formation of benzoic acid.
\end{abstract}

\section{Introduction}

Carbon dioxide $\left(\mathrm{CO}_{2}\right)$ is the final, stable compound obtained in the oxidation of carbon compounds and is boundless resources in the carbon cycles. In order to use the carbon resources effectively, the electrochemical fixation of $\mathrm{CO}_{2}$ to organic compounds has been markedly developed. The electroreduction of $n$-butyl bromide in the presence of $\mathrm{CO}_{2}$ on a $\mathrm{Hg}$ cathode in dimethylformamide (DMF) produces dibutylmercury, dibutyl oxalate, and butyl valerate ${ }^{1)}$;

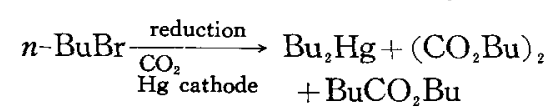

In this reaction the formation of the anion radical of $\mathrm{CO}_{2}\left(\mathrm{CO}_{2}^{-}\right)$is essential to fixate $\mathrm{CO}_{2}$ on the butyl group; electrolysis at a potential, where only butyl bromide is reduced (and $\mathrm{CO}_{2}$ not reduced), yields no estersn or acids.

We report herein the electrochemical reduction of aromatic halides (iodobenzene, bromobenzene, chlorobenzene) with a $\mathrm{Hg}$ cathode under $\mathrm{CO}_{2}$. The reduction of iodobenzene produced benzoic acid as a fixated product of $\mathrm{CO}_{2}$ on the phenyl group at a potential where only iodobenzene is reduced (whereas $\mathrm{CO}_{2}$ not reduced). It appears that the reduction mechanism for the present electrolysis of halobenzenes is somewhat different from that for the electrochemical reduction of alkyl halides under $\mathrm{CO}_{2}$.

\section{Experimental}

DMF was dried over $\mathrm{Na}_{2} \mathrm{SO}_{4}$ or $\mathrm{Na}_{2} \mathrm{CO}_{3}$ for

\footnotetext{
* Pharmaceutical Institute, Tohoku University (Aobayama, Sendai, Miyagi)

Key Words : Carboxylation, Carbon Dioxide, Halobenzene, Iodobenzene, Benzoic Acid
}

several days and distilled at a reduced pressure prior to use. Tetraethylammonium perchlorate (TEAP) was synthesized and purified by the reported $\operatorname{method}^{2}$. Halobenzenes were purchased commercially and were distilled before use.

Cyclic voltammetry was carried out using conventional instruments with hanging mercury drop electrode (HMDE) or a $\mathrm{Hg}$ coated $\mathrm{Pt}$ wire electrode as the working electrode and a $\mathrm{Pt}$ wire counter electrode in DMF solution containing $0.1 \mathrm{M}\left(\mathrm{mol} \mathrm{dm}^{-3}\right)$ TEAP. The potentials were referenced to a saturated calomel electrode (SCE) with multi-junction to prevent contamination from water or $\mathrm{KCl}$.

All macro-electrolyses were performed with a Yanaco VE-8 controlled potential electrolyzer. The cell was a divided $\mathrm{H}$-type with a $\mathrm{Hg}$ pool cathode (area $c a .6 \mathrm{~cm}^{2}$ ), a $\mathrm{Pt}$ gauze anode and an SCE with the multi-junction. The catholyte consisted of $20 \mathrm{~cm}^{3}$ DMF solution containing halobenzenes and $0.1 \mathrm{M}$ TEAP, continuously bubbled with $\mathrm{CO}_{2}$ or $\mathrm{N}_{2}$ gas.

After the electrolysis the catholyte was acidified with diluted $\mathrm{HCl}$, extracted with ether, and then concentrated for gas chromatography. Gas chromatographic analyses were carried out with a Shimadzu GC-6 A machine equipped with a hydrogen flame ionization detector; columns used for the analyses were a $2 \mathrm{~m} \times 3 \mathrm{~mm} \phi$ SUS packed with Carbowax $20 \mathrm{M}$ on Chromosorb $\mathrm{W}$ and a $1.5 \mathrm{~m} \times 3 \mathrm{~mm} \phi$ SUS packed with DEGS $\left(+5 \% \mathrm{H}_{3} \mathrm{PO}_{4}\right)$ on Diasolid M. Nitrogen was used as the carrier gas. The determination of benzene, benzoic acid, and the unreacted halobenzenes were performed from the gas chromatographic data by comparison with calibration 
lines of authentic samples. Diphenylmercury was detected by TLC (hexane : ethyl acetate $=$ $10: 1$ ).

\section{Results and Discussion \\ 3.1 Controlled potential macro-electrol- ysis}

The controlled potential macro-electrolyses of iodobenzene were carried out with a $\mathrm{Hg}$ pool cathode at $-1.8 \mathrm{~V}$ vs. SCE. At the potential only iodobenzene is reduced (whereas $\mathrm{CO}_{2}$ not reduced). The results are summarized in Table 1. Under $\mathrm{CO}_{2}$ benzoic acid was obtained as a main product. In all cases, benzene, small amounts of diphenylmercury, and some other unidentified products were detected. The yield of benzoic acid (based on the amount of the consumed iodobenzene) is almost independent of the initial concentration of iodobenzene. The formation of diphenylmercury may suggest the participation of the $\mathrm{Hg}$ cathode as a reactant in the reduction. In the present electrolyses, phenyl benzoate, phenol, or biphenyl could not be detected. The addition of phenol as a proton source resulted in an increase of the yield of benzene.

The electroreduction of bromobenzene under $\mathrm{CO}_{2}$ also produced benzoic acid, small amounts of diphenylmercury, and some other unidentified products (Table 2). In this case, the cathode potential was set at $-2.3 \mathrm{~V}$ vs. SCE where both bromobenzene and $\mathrm{CO}_{2}$ are reduced. The current efficiencies for the formation of benzoic acid in this case were quite low compared with those in the electroreduction of iodobenzene. This indicates that most of charge was consumed by the reduction of $\mathrm{CO}_{2}$ to $\mathrm{CO}_{2}{ }^{-}$and
'Table 2 Macro-electrolysis of bromobenzene under $\mathrm{CO}_{2}$

\begin{tabular}{c|c|c|r|r|r}
\hline \hline Run & $\begin{array}{c}\text { Conv. } \\
1 \%\end{array}$ & $\begin{array}{c}\text { Passed charge } \\
\times 10^{-5} / \mathrm{C} \mathrm{\text {mol } ^ { - 1 }}\end{array}$ & \multicolumn{2}{|c|}{ Yield/\% } & $\begin{array}{c}\text { PhH } \\
\text { Ph.E. }\end{array}$ \\
\hline 1 & 26 & 0.9 & & 36 & 20 \\
2 & 50 & 2.2 & 9 & 37 & 16 \\
3 & 63 & 3.0 & 13 & 38 & 15 \\
4 & 88 & 6.0 & 21 & 39 & 11 \\
\hline
\end{tabular}

Initial concentration of bromobenzene: $46 \mathrm{mM}$, Solvent: 0.1 M TEAP/DMF, Cathode: Hg pool (area $c a .6 \mathrm{~cm}^{2}$ ), Cathode potential: $-2.3 \mathrm{~V}$ vs. SCE

the reactivity of $\mathrm{CO}_{2}{ }^{-}$with bromobenzene may be low.

The electroreduction of $\mathrm{CO}_{2}$ in the presence of chlorobenzene was also carried out at -2.3 $\mathrm{V}$ vs. SCE where only $\mathrm{CO}_{2}$ is reduced (whereas chlorobenzene not reduced). In this case, no benzoic acid was detected.

$$
\mathrm{PhCl} \frac{\mathrm{CO}_{8}}{\begin{array}{c}
-2.3 \mathrm{~V} \\
\begin{array}{c}
2.5 \times 10^{5} \mathrm{vs} . \mathrm{mol}^{-1} \\
\mathrm{Hg} \text { cathode }
\end{array}
\end{array}} \text { no benzoic acid }
$$

Therefore the following is deduced; the reduction of halobenzenes is important for the fixation of $\mathrm{CO}_{2}$ to the phenyl group and the reactivity of $\mathrm{CO}_{2}^{-}$with halobenzenes, if any, is low. The above is contrast well with the electroreduction of alkyl halides on a $\mathrm{Hg}$ cathode under $\mathrm{CO}_{2}$, in which the formation of $\mathrm{CO}_{2}-$ is essential to fixate $\mathrm{CO}_{2}$ on the alkyl group ${ }^{32}$.

\subsection{Cyclic voltammetry}

Figure 1 depicts the cyclic voltammograms of $1.0 \mathrm{mM}$ iodobenzene under $\mathrm{N}_{2}$ and under saturated $\mathrm{CO}_{2}$, together with that of $\mathrm{CO}_{2}$, on an HMDE in DMF solution. Iodobenzene shows

Table 1 Macro-electrolysis of iodobenzene under $\mathrm{CO}_{2}$

\begin{tabular}{|c|c|c|c|c|c|c|}
\hline \multirow{2}{*}{ Run } & \multirow{2}{*}{ Conc. of $\mathrm{PhI} / \mathrm{mM}$} & \multirow{2}{*}{ Conv. ${ }^{2}>/ \%$} & \multirow{2}{*}{$\begin{array}{l}\text { Passed charge } \\
\times 10^{-5} / \mathrm{C} \mathrm{mol}^{-1}\end{array}$} & \multicolumn{2}{|c|}{ Yield ${ }^{b} / \%$} & \multirow{2}{*}{ C.E.c $>/ \mathscr{O}$} \\
\hline & & & & $\mathrm{PhH}$ & $\mathrm{PhCOOH}$ & \\
\hline 1 & 10 & 87 & 1.3 & 12 & 33 & 43 \\
\hline 2 & 20 & 53 & 1.0 & 2 & 35 & 36 \\
\hline 3 & 50 & 77 & 1.1 & 7 & 40 & 54 \\
\hline $4^{\mathrm{d}\rangle}$ & 50 & 49 & 1.0 & 30 & 0 & \\
\hline
\end{tabular}

a) Conversion of iodobenzene, b) Based on the amount of consumed iodobenzene, c) Current efficiency for the formation of benzoic acid, d) Under $\mathrm{N}_{z}$ in the presence of $c a .0 .1 \mathrm{M}$ phenol Solvent: $0.1 \mathrm{M}$ TEAP/DMF, Cathode: $\mathrm{Hg}$ pool (area $c a .6 \mathrm{~cm}^{2}$ ), Cathode potential: $-1.8 \mathrm{~V} v s$. SCE 


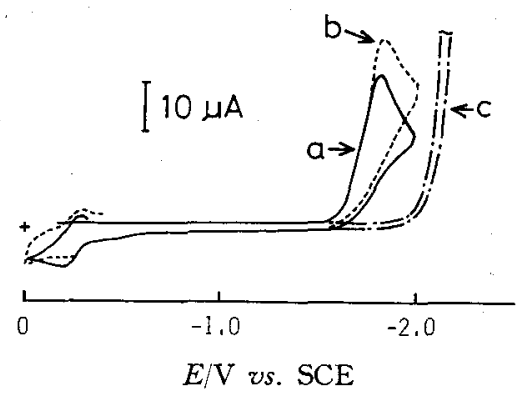

Fig. 1 Cyclic voltammograms of $1.0 \mathrm{mM}$ iodobenzene under $\mathrm{N}_{2}$ (a) and under saturated $\mathrm{CO}_{2}$ (b). Curve (c) represents the cyclic voltammogram of $\mathrm{CO}_{2}$ Electrolyte : 0.1 M TEAP/DMF, Electrode : HMDE, Scan rate: $80 \mathrm{mV} \mathrm{s}^{-1}$

an irreversible reduction peak at $-1.80 \mathrm{~V}$ vs. SCE and reversible peak at $c a .-0.3 \mathrm{~V}$ vs. $\mathrm{SCE}$ which is originated from the redox reaction of $\mathrm{Hg} / \mathrm{Hg}_{2} \mathrm{I}_{2}$; the iodide ion is splitted off from the parent compound in the course of the reduction. The onset potential for the reduction of $\mathrm{CO}_{2}$ appears at $c a .-2.0 \mathrm{~V}$ vs. SCE; therefore, $\mathrm{CO}_{2}$ is more difficult to be reduced than iodobenzene. The peak current analysis suggests that the reduction of iodobenzene is not twoelectron process. The saturation of the electrolyte solution with $\mathrm{CO}_{2}$ resulted in ca. 1.2 fold increase in the peak current. The same increase was also observed by the addition of phenol as a proton source under $\mathrm{N}_{2}$ (Fig. 2). These phenomena may indicate that the reduction process approaches two-electron uptake by the addition of $\mathrm{CO}_{2}$ or proton and that $\mathrm{CO}_{2}$ molecule influences the reduction in a same way as proton.

On the $\mathrm{Hg}$ electrode the reduction peak potential of iodobenzene is observed to be exceptionally positive compared with those on the other types of electrodes. For instance, on a plate electrode of $\mathrm{Pt}$, glassy carbon or $\mathrm{SnO}_{2}$, the reduction peak appeared at more negative potentials than $-2.0 \mathrm{~V}$ vs. SCE, indicating the participation of the $\mathrm{Hg}$ electrode as a reactant in the course of the reduction. This is reinforced by the result of macro-electrolysis in which a small amount of diphenylmercury was detected in the reaction products. The participation of a $\mathrm{Hg}$ electrode as a reactant has been frequently observed in the electroreduction of organic halides ${ }^{3}$ )

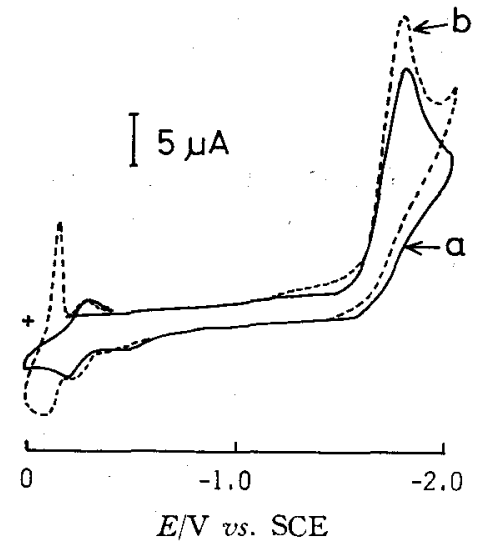

Fig. 2 Cyclic voltammograms of $1.0 \mathrm{mM}$ iodobenzene in the absence (a) and presence (b) of ca. $10 \mathrm{mM}$ phenol under $\mathrm{N}_{2}$

Electrolyte : $0.1 \mathrm{M}$ TEAP/DMF, Electrode : HMDE, Scan rate: $82 \mathrm{mV} \mathrm{s}^{-1}$

or organometallic compounds ${ }^{4}$. The electrochemical reduction of some alkyl halides on a $\mathrm{Hg}$ electrode yields organomercury compounds almost quantitatively ${ }^{5)}$. The participation of $\mathrm{Hg}$ has also been observed in the electroreduction of iodobenzene even in an aqueous media ${ }^{6}$. Therefore, in aprotic solvent, e.q., DMF, the $\mathrm{Hg}$ electrode may influence the reduction of halobenzenes more significantly. In the reduction of tetraphenylstibonium ion on a $\mathrm{Hg}$ cathode in an aqueous solution, the phenylmercury radical $\left(\mathrm{PhHg}^{*}\right)$ has been considered as an intermediate for the formation of benzene ${ }^{7}$.

$$
\begin{aligned}
& \mathrm{Ph}_{4} \mathrm{Sb}^{+}+\mathrm{Hg}+\mathrm{e} \longrightarrow \mathrm{Ph}_{3} \mathrm{Sb}+\mathrm{PhHg}{ }^{\cdot} \\
& \mathrm{PhHg}^{-} \longrightarrow 1 / 2 \mathrm{Ph}_{2} \mathrm{Hg}+1 / 2 \mathrm{Hg} \\
& \mathrm{PhHg} \cdot+\mathrm{H}^{+}+\mathrm{e} \longrightarrow \mathrm{PhH}+\mathrm{Hg}
\end{aligned}
$$

The radical would also be the intermediate in the present electrolysis. Therefore, the following mechanism is deduced for the present electrolysis.

$$
\begin{aligned}
& \mathrm{PhX}+\mathrm{Hg}+\mathrm{e} \longrightarrow \mathrm{PhHg}^{*}+\mathrm{X}^{-} \\
& \mathrm{PhHg} \longrightarrow 1 / 2 \mathrm{Ph}_{2} \mathrm{Hg}+1 / 2 \mathrm{Hg} \\
& \mathrm{PhHg} \cdot+\mathrm{CO}_{2}+\mathrm{e} \longrightarrow \mathrm{PhCO}_{2}++\mathrm{Hg} \\
& \mathrm{PhHg}+\left\{\begin{array}{l}
\mathrm{SH} \\
\mathrm{H}_{2} \mathrm{O}(\text { residual })+\mathrm{e} \longrightarrow \\
\mathrm{Et}_{3} \mathrm{~N}^{+} \mathrm{CH}_{2} \mathrm{CH}_{3}
\end{array}\right. \\
& \mathrm{PhH}+\left\{\begin{array}{l}
\mathrm{S}^{-} \\
\mathrm{OH}^{-} \\
\mathrm{Et}_{3} \mathrm{~N}+\mathrm{CH}_{3}=\mathrm{CH}_{2}
\end{array}+\mathrm{Hg}\right. \\
& \mathrm{SH}=\mathrm{DMF} ; \mathrm{X}=\mathrm{I}, \mathrm{Br}
\end{aligned}
$$


The solvent, the supporting electrolyte, or the residual water acts as a hydrogen source for the benzene formation ${ }^{5,8}$. The reduction of bromobenzene under $\mathrm{CO}_{2}$ would proceed via the same mechanism as that of iodobenzene, although the effect of $\mathrm{CO}_{2}$ on the reduction could not be demonstrated since the reduction peak potential of bromobenzene $(-2.35 \mathrm{~V}$ vs. SCE) is more negative than that of $\mathrm{CO}_{2}$ as shown in Fig. 3.

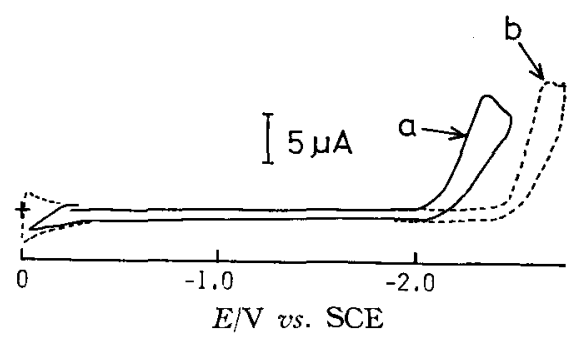

Fig. 3 Cyclic voltammograms of $1.0 \mathrm{mM}$ bromobenzene (a) and $1.0 \mathrm{mM}$ chlorobenzene (b) under $\mathrm{N}_{2}$

Electrolyte : 0.1 M TEAP/DMF, Electrode : $\mathrm{Hg}$ coated $\mathrm{Pt}$ wire, Scan rate: $100 \mathrm{mV} \mathrm{s}^{-1}$

The same argument may also be applicable to the reduction of chlorobenzene. It is also notable that the reaction of $\mathrm{CO}_{2}-$ with bromobenzene and chlorobenzene, if any, is slow, which is deduced from the results of macro-electrolyses.

$$
\begin{gathered}
\mathrm{CO}_{2}{ }^{-}+\mathrm{PhX} \longrightarrow \text { no or slow reaction } \\
\mathrm{X}=\mathrm{Br}, \mathrm{Cl}
\end{gathered}
$$

However, the detailed mechanism for the present reaction is still unclear; further investigations about the reduction is now underway.

\section{Conclusion}

The electroreduction of iodobenzene and bromobenzene under $\mathrm{CO}_{2}$ yielded benzoic acid as a fixation product of $\mathrm{CO}_{2}$ to the phenyl group. However, the reduction of $\mathrm{CO}_{2}$ in the presence of chlorobenzene produced no benzoic acid. Therefore, it is deduced that the reduction of halobenzene is important to fixate $\mathrm{CO}_{2}$ to the phenyl group and the reactivity of $\mathrm{CO}_{2}^{-}$with halobenzenes is low. In the present reaction, the phenylmercury radical is considered as an intermediate for the formation of benzoic acid.

\section{References:}

1) J.H. Wagenknecht, J. Electroanal. Chem. 52, 489 (1974); D.A. Tyssee, J.H. Wagenkecht, M.M. Baizer and J.L. Chruma, Tetrahedron Lett., 4809 (1972).

2) T. Fujinaga, K. Izutsu and K. Takaoka, J. Electroanal. Chem. 12, 203 (1966).

3) M.R. Rifi in M.M. Baizer (ed), “Organic Electrochemistry”, Ch. VI, Marcel Dekker, 1973.

4) W.J. Settineri and L.D. McKeever in N.L. Weinberg (ed), "Technique of Electroorganic Synthesis", Ch. X, John Wiley \& Sons, 1974.

5) D.M. La Perriere, W.F. Carroll, Jr., B.C. Willett, E.C. Torp and D.G. Peters, J.Amer. Chem. Soc. 101, 7561 (1979).

6) S.G. Mairanovskii, T.Ya. Rubinskaya and I.V. Proskurovskaya, Elektrokhimiya 11, 1386 (1975).

7) M.D. Morris, P.S. McKinney and E.C. Woodbury, J. Electroanal. Chem. 10, 85 (1965); G.R. Williams and P.S. McKinney, J.Electroanal. Chem. 30, 131 (1971).

8) J.L. Webb, C.K. Mann and H.M. Walborsky, $J$. Amer. Chem. Soc. 92, 2042 (1970).

(Received Mar. 1, 1982 ; Accepted Jun. 17, 1982) 